\title{
Biofilm Formation and Phenotypic Detection of ESBL, MBL, KPC and AmpC Enzymes and Their Coexistence in Klebsiella spp. Isolated at the National Reference Laboratory, Kathmandu, Nepal
}

\author{
Susmita Kuinkel ${ }^{1}$, Jyoti Acharya ${ }^{2} \oplus$, Binod Dhungel ${ }^{1} \oplus$, Sanjib Adhikari ${ }^{1}$, Nabaraj Adhikari ${ }^{1}$, \\ Upendra Thapa Shrestha ${ }^{1}$ (1), Megha Raj Banjara ${ }^{1}$, Komal Raj Rijal ${ }^{1, *} \mathbb{C}$ and Prakash Ghimire ${ }^{1}$ (I)
}

1 Central Department of Microbiology, Tribhuvan University, Kirtipur, Kathmandu 44600, Nepal; kuinkel.susmita@gmail.com (S.K.); bwith.binod@gmail.com (B.D.); sanadh26@gmail.com (S.A.); adhikarinaba13@gmail.com (N.A.); upendrats@gmail.com (U.T.S.); banjaramr@gmail.com (M.R.B.); prakashghimire@gmail.com (P.G.)

2 National Public Health Laboratory, Teku, Kathmandu 44600, Nepal; jyotigan30@gmail.com

* Correspondence: rijalkomal@gmail.com or komal.rijal@cdmi.tu.edu.np

check for

updates

Citation: Kuinkel, S.; Acharya, J.;

Dhungel, B.; Adhikari, S.;

Adhikari, N.; Shrestha, U.T.;

Banjara, M.R.; Rijal, K.R.; Ghimire, P.

Biofilm Formation and Phenotypic

Detection of ESBL, MBL, KPC and

AmpC Enzymes and Their

Coexistence in Klebsiella spp. Isolated

at the National Reference Laboratory,

Kathmandu, Nepal. Microbiol. Res.

2021, 12, 683-697. https://doi.org/

10.3390/microbiolres12030049

Academic Editors:

Yiannis Kourkoutas and

Michael Calcutt

Received: 22 April 2021

Accepted: 29 July 2021

Published: 18 August 2021

Publisher's Note: MDPI stays neutral with regard to jurisdictional claims in published maps and institutional affiliations.

Copyright: (c) 2021 by the authors. Licensee MDPI, Basel, Switzerland. This article is an open access article distributed under the terms and conditions of the Creative Commons Attribution (CC BY) license (https:/ / creativecommons.org/licenses/by/ $4.0 /)$.

\begin{abstract}
Klebsiella spp. are associated with several nosocomial and opportunistic infections. Increasing antimicrobial resistance of Klebsiella species is aggravated by a number of intrinsic and extrinsic factors. The main aim of this study is to determine antimicrobial resistance due to production of $\beta$-lactamase enzymes, extended spectrum beta-lactamase (ESBL), metallo-beta-lactamase (MBL) and AmpC and Klebsiella pneumoniae carbapenemase (KPC) and biofilm formation in Klebsiella isolates. A total of 2197 non-duplicate specimens of urine, sputum and pus were obtained from the National Public Health Laboratory (NPHL), Kathmandu, Nepal, between February and August 2019. Klebsiella species were isolated, identified and screened for antimicrobial susceptibility testing with the disk diffusion method. Phenotypic detection of ESBL, MBL, KPC and AmpC production was observed and biofilm production was detected by the microtiter plate method. Out of a total of 2197 clinical specimens, bacterial growth was detected in $8 \%(175 / 2197)$ of the specimens. Of the total isolates, $86.3 \%(151 / 175)$ were Gram-negative bacteria and 37.7\% (57/151) were Klebsiella spp. Of the total Klebsiella spp., 56\% (32/57) were multi drug resistant (MDR), 16\% (9/57) were ESBL, 26\% (15/57) were MBL, 4\% (2/57) were KPC (class A carbapenemase), 16\% (9/57) were AmpC producers and $95 \%$ (54/57) were biofilm producers. Gentamicin was the most effective antibiotic, followed by cotrimoxazole, as $68 \%(39 / 57)$ and $47 \%(27 / 57)$ of the Klebsiella isolates were susceptible towards these drugs, respectively. The study results show evidence of $\beta$-lactamase production, high prevalence of MDR and biofilm producing Klebsiella species. Integrating the test parameters for phenotypic confirmation of ESBL, MBL, AmpC $\beta$ lactamase and KPC in routine diagnostic procedures can help in the early detection and management of these resistant strains.
\end{abstract}

Keywords: antimicrobial resistance; multi drug resistant (MDR); extended-spectrum $\beta$-lactamase (ESBL); AmpC $\beta$-lactamase (ABL); carbapenemase; biofilm

\section{Introduction}

Klebsiella species are Gram-negative, non-motile, encapsulated, lactose-fermenting and facultative anaerobic bacteria that cause several diseases, especially in countries with a poor health system [1]. K. pneumoniae, its subspecies (K. pneumoniae, K. ozaenae and K. rhinoscleromatis) and K. oxytoca are the frequently isolated and medically important members of this genus [2]. Despite being normal flora organisms of the human gastrointestinal tract, K. pneumoniae is the most common pathogenic agent of nosocomial infections among Klebsiella spp. [3]. Pneumonia, urinary tract infection (UTI), blood stream and surgical wound infections, peritonitis, septicemia, meningitis [4] and pyogenic liver abscess [5] 
are the major diseases caused by K. pneumoniae in humans. Antimicrobial resistance of Enterobacteriaceae (mainly Escherichia. coli, K. pneumoniae and Salmonella spp.) has increased dramatically in recent years $[4,5]$. These pathogens have developed resistance against commonly used antimicrobial agents, such as the extended-spectrum beta-lactams, aminoglycosides, fluoroquinolones and carbapenems [4,5]. Therefore, drug-resistance problems are responsible for narrowed therapeutic options, increased cost of treatment, prolonged hospital stays and mortality [6,7].

The pathogenicity of Klebsiella species is attributable to a number of virulence factors, such as capsule, lipopolysaccharide (LPS), fimbrial and non-fimbrial adhesins, siderophores [8] and their ability to form biofilm [9]. Biofilms are the bacterial aggregates firmly lodged in the extracellular matrices of polysaccharides, proteins, enzymes and nucleic acid which facilitate anchoring to any surface irreversibly [10]. Because of their ability to form biofilms, infections caused by K. pneumoniae are becoming more challenging and warrant the need for innovative anti-biofilm approaches [11]. An examination utilizing signature labeled mutagenesis and surfaces covered with human extracellular framework (HECM) distinguished a protein associated with capsule biosynthesis essential for the biofilm production by K. pneumoniae [12]. A recent report indicated that capsule genes wza and ORF14 are essential for K. pneumoniae to develop biofilm [13].

$\beta$-lactamase enzymes, such as extended-spectrum $\beta$-lactamase (ESBL), AmpC $\beta$ lactamases and carbapenemase, are responsible for resistance to $\beta$-lactam antibiotics such as penicillins, cephamycin and carbapenem [14,15]. Carbapenems are used as the last resort drug for the life-threatening infections caused by multi drug resistant (MDR) pathogens and ESBL-producing Enterobacteriaceae [16-18]. However, over the past few years, due to the selective pressure of treating the ESBL and AmpC infections with carbapenems, resistance has emerged and K. pneumoniae is the most common carbapenem resistant Enterobacteriaceae (CRE) [19]. Prevalence of Klebsiella pneumoniae carbapenemases (KPC) and metallo- $\beta$ - lactamase producing strains among K. pneumoniae have been explored in different countries [19]. Carbapenem resistance due to metallo-beta-lactamase (MBL) production has been increasingly reported among clinical isolates from all around the world [20]. The rapidly increasing rate of MBL production among the members of Enterobacteriaceae, mainly E. coli and K. pneumoniae, has become one of the most common causes of hospital infections with limited therapeutic options [21]. A reliable estimate of the extent of drug resistant isolates of K. pneumoniae is thus essential to inform the control and management of hygiene and infection and treatment options for drug resistant strains.

While there have been a number of studies exploring production of beta-lactamase enzymes among Klebsiella species worldwide [22-24], there is a paucity of such studies in Nepal. The studies on biofilm mediated resistance and the resistance due to co-expression of beta-lactamase enzymes are sparse [25-27]. A few previous studies in Nepal have reported the varying prevalence of Klebsiella spp. For instance, the prevalence of nosocomial infections by Klebsiella spp. was $8.1 \%$ in a tertiary health care center in Bhairahawa [28], $15.6 \%$ in the Alka Hospital, Lalitpur [29] and 21.6\% in the Tribhuvan University Teaching Hospital, Kathmandu [30]. The main objective of this study is to explore the burden of ESBL, AmpC, MBL, KPC and biofilm producing Klebsiella species, in addition to assessing co-existence of these factors and their role in development of drug resistance. This is a crosssectional study carried out at the National Public Health Laboratory (NPHL), Kathmandu, between February and August 2019.

\section{Materials and Methods}

\subsection{Study Design and Study Sample}

A total of 2197 samples were processed and analyzed at NPHL. Specimens (total, $n=2197)$ in this study constituted of urine $(n=2032)$, sputum $(n=150)$ and pus $(n=15)$. These specimens were obtained in a sterile, clean, well-labeled and leak-proof container with no visible signs of contamination and were transported to the laboratory [31]. 


\subsection{Sample Collection and Transportation}

About 10-20 mL of early morning mid-stream urine (MSU) was collected in welllabeled, sterile, dry, wide-mouthed and leak-proof plastic container. Urine specimens that showed polymicrobial growth were not included in our study. Sputum samples were requested to be collected at early morning without a mix of saliva or nasal discharge and were collected in a wide-mouth leak-proof, disposable plastic container. In case of pus, a sterile cotton swab or aspirated syringes were used to collect the deepest portion of lesion or exudates rather than superficial debris. All the collected specimens were transported to the laboratory [32].

\subsection{Macroscopic and Microscopic Examinations}

Samples were examined for color, consistency, turbidity, presence of blood and pus based on the standard guidelines. Gram-stained smears of suitable specimens such as pus and sputum were prepared on a clean, grease-free glass slide and observed through a microscope for the presence of bacteria and pus cells [32,33].

\subsection{Culture of Specimens and Identification of the Isolates}

Sputum and pus samples were inoculated on blood agar and MacConkey agar, while urine was inoculated on Cysteine Lactose Electrolyte Deficient (CLED) agar using a standard calibrated loop $(4 \mathrm{~mm})$. All the inoculated media were incubated at $37^{\circ} \mathrm{C}$ in aerobic conditions for 18-24 h. Thus, the obtained colony growths having Gram-negative rods suspected of Klebsiella spp. were further sub-cultured aerobically on nutrient agar (NA) overnight. Identification and confirmation of isolates were performed using microbiological tools and techniques such as colony morphology, staining and biochemical tests [32,33].

\subsection{Antibiotic Susceptibility Testing}

All identified bacterial isolates of Klebsiella spp. were tested for susceptibility against amoxiclav $(30 \mu \mathrm{g})$, ceftriaxone $(30 \mu \mathrm{g})$, ciprofloxacin $(5 \mu \mathrm{g})$, cotrimoxazole $(25 \mu \mathrm{g})$, norfloxacin $(10 \mu \mathrm{g})$, nitrofurantoin $(30 \mu \mathrm{g})$, cefotaxime $(30 \mu \mathrm{g})$, gentamicin $(10 \mu \mathrm{g})$, piperacillintazobactam $(100 / 10 \mu \mathrm{g})$, amikacin $(30 \mu \mathrm{g})$, tetracycline $(30 \mu \mathrm{g})$, levofloxacin $(5 \mu \mathrm{g})$, imipenem $(10 \mu \mathrm{g})$, meropenem $(10 \mu \mathrm{g})$ and cefoxitin $(30 \mu \mathrm{g})$ (HiMedia India Pvt. Ltd., Bengaluru, India), following the Kirby-Bauer method on Mueller-Hinton Agar (HiMedia India Pvt. Ltd.). Interpretation of results was based on the Clinical and Laboratory Standard Institute (CLSI) [34]. Isolates showing non-susceptibility (either a resistant or intermediate) to at least one antimicrobial agent in three or more of the categories were considered as multi-drug resistant [35].

\subsection{Screening and Confirmation of ESBL Producers}

The bacterial isolates were screened for possible ESBL production using ceftazidime $(30 \mu \mathrm{g})$, cefotaxime $(30 \mu \mathrm{g})$ and ceftriaxone $(30 \mu \mathrm{g})$. Isolates showing reduced susceptibility to one or all of these drugs with zone of inhibition diameter for ceftazidime $\leq 22 \mathrm{~mm}$, cefotaxime $\leq 27 \mathrm{~mm}$, ceftriaxone $\leq 25 \mathrm{~mm}$ and aztreonam $\leq 27 \mathrm{~mm}$ were considered as possible ESBL producing isolates [29]. A phenotypic confirmation of ESBL was based on the combination disc method. A difference of $\geq 5 \mathrm{~mm}$ zone diameter of either cephalosporin discs or their respective cephalosporin-clavulanate disc was taken as phenotypic confirmatory test [34].

\subsection{Screening and Confirmation of MBL Producers}

Isolates resistant to carbapenems, such as imipenem $(10 \mu \mathrm{g})$ or meropenem $(10 \mu \mathrm{g})$, by disk diffusion test were suspected for possible MBL production. Phenotypic confirmation of MBL producers was performed by the imipenem-EDTA disk diffusion method. For this method, two imipenem disks $(10 \mu \mathrm{g})$ were placed $20 \mathrm{~mm}$ apart and $5 \mu \mathrm{L}$ of $0.5 \mathrm{M}$ EDTA solution was added to one of the disks. The inhibition zones of the imipenem and imipenem-EDTA disc were compared after $16-18 \mathrm{~h}$ of incubation at $37^{\circ} \mathrm{C}$ aerobically. The 
increase in zone of inhibition of the imipenem and EDTA disk $\geq 7 \mathrm{~mm}$ than the imipenem disk alone was confirmed as MBL positive [36].

\subsection{Screening and Phenotypic Confirmation of KPC Producers}

Isolates confirmed as carbapenem resistant in previous disc diffusion tests were screened for possible phenotypic KPC production using the meropenem-phenyl boronic acid (PBA) disk diffusion method. Two meropenem discs $(10 \mu \mathrm{g})$ were placed on the plate at a distance of $20 \mathrm{~mm}$ and $20 \mu \mathrm{L}$ (containing $400 \mu \mathrm{g}$ of PBA) solution of concentration $20 \mathrm{mg} / \mathrm{mL}$ was added to one of the disc. The inhibition zones of the meropenem and meropenem disk with PBA were compared after $16-18 \mathrm{~h}$ of incubation at $37^{\circ} \mathrm{C}$ aerobically. The increase in zone of inhibition with the meropenem disk with PBA $\geq 5 \mathrm{~mm}$ than the meropenem disk alone was confirmed as a KPC producer [37].

\subsection{Screening and Confirmation of AmpC Producers}

Bacterial isolates showing resistant or intermediate $(\leq 18 \mathrm{~mm})$ onto a cefoxitin (CX) were screened as AmpC producers, which was further confirmed by an inhibition-based method. For this method, a PBA solution was prepared by dissolving $120 \mathrm{mg}$ of PBA in $3 \mathrm{~mL}$ of DMSO (Dimethyl sulfonic acid) into which $3 \mathrm{~mL}$ of sterile distilled water was added. A volume of $20 \mu \mathrm{L}$ of the stock solution of PBA solution was dispensed onto a cefoxitin $(30 \mu \mathrm{g})$ disc. By using the standard disk diffusion method, the cefoxitin disc $(30 \mu \mathrm{g})$ and cefoxitin $(30 \mu \mathrm{g})$ disc with PBA $(400 \mu \mathrm{g})$ were placed on an MHA plate already inoculated with the test strain. The inoculated plates were then incubated overnight at $37^{\circ} \mathrm{C}$. An organism showing an increase of $\geq 5 \mathrm{~mm}$ of zone diameter around the cefoxitin disk alone was considered as an AmpC producer [38].

\subsection{Detection of Biofilm Formation by Micro-Titer Plate Method}

Biofilm production by the isolates was detected by a micro-titer plate method. For this method, a fresh loopful of test organism was inoculated into $10 \mathrm{~mL}$ of trypticase soya broth (TSB) with $1 \%$ glucose and incubated at $37^{\circ} \mathrm{C}$ for $24 \mathrm{~h}$. After incubation, the solution was diluted (1:100) with fresh TSB. Then, $200 \mu \mathrm{L}$ of diluted culture broth were added to each well of a microtiter plate having 96 wells. TSB with $1 \%$ glucose was used as the negative control. The plate was then incubated at $37^{\circ} \mathrm{C}$ for $24 \mathrm{~h}$. After incubation, the content of each well was removed by gentle tapping and wells were washed with $200 \mu \mathrm{L}$ of PBS 3-4 times to remove the free-floating bacteria. Biofilm formed by the bacteria adherent to the wells was fixed by $2 \%$ sodium acetate and then stained by $0.1 \%$ crystal violet. Excess stain was removed by washing the plate with de-ionized water and the plate was dried. Finally, all wells were filled with $200 \mu \mathrm{L}$ ethanol (95\%) to release the dye from the cells. Optical density (OD) of stained adherent biofilm was then recorded with the help of a microtiter reader at the wavelength of $630 \mathrm{~nm}$ and results were interpreted as weak, moderate and strong biofilm producers. The optical density cut-off value (ODc) was determined by arithmetically averaging the OD of the wells containing sterile TSB broth and adding a standard deviation of +2 . Samples with an OD higher than the cut-off value were considered positive, whereas those with the lower optical density than the cut-off value were considered as negative. Strains were classified using the following criteria: $\leq$ ODc or ODc $<-\geq 2 \times$ ODc, non-biofilm producer; $2 \times$ ODc $<-\leq 4 \times$ ODc, moderate biofilm producer; $>4 \times$ ODc, strong biofilm producer $[39,40]$ (Figure 1 ).

\subsection{Quality Control}

Stringent measures were utilized to ensure the quality standard and aseptic conditions. Each batch of media and the reagents, including antibiotic disks, were assured according to the CLSI guidelines. Purity plates were used to check the pure culture of the isolates and aseptic standards during biochemical tests. Control strains of E. coli ATCC 25922 and Staphylococcus aureus ATCC 25923 were used during the antibiotic susceptibility test (AST). 




Figure 1. Biofilm production test by the microtiter plate method: negative control (A1, A2, A3), strong producer (F10, F11, F12), moderate producer (B10, B11, B12), weak producer (H7, H8, H9) and non-producer (H4, H5, H6). NB: The higher the ODc, the higher the concentration of the purple color in the presented microtiter well. Concentration of color represents the strength of producing the biofilms from higher to lower as the concentration decreases.

\subsection{Data Analysis}

Data were entered into an excel spreadsheet and analyzed using SPSS Version 24 (IBM; Chicago, IL, USA) accessed on March, 2019. Categorical data were analyzed using the Chi-squared test. A $p$ value of $<0.05$ was considered as statistically significant.

\section{Results}

\subsection{Distribution of Growth Pattern of Bacterial Isolates}

A total of 2197 different clinical specimens were processed for microbial culture, of which $175(8.3 \%)$ showed growth of bacteria. Out of the 175 isolates, 151 (86.3\%) were Gram-negative bacteria and 24 (13.7\%) were Gram-positive bacteria. Among 151 Gram-negative isolates, $121(80 \%)$ were from urine, followed by $28(19 \%)$ from sputum and $2(1 \%)$ from pus specimens, whereas, among 24 Gram-positive isolates, $19(79.2 \%)$ were from urine, followed by pus sample $(5 ; 20.8)$. Among the Gram-negative bacteria, E. coli $(41.1 \%$; 62/151) was the predominant organism, followed by K. pneumoniae $(26.5 \%$; 40/151), K. oxytoca (11.3\%; 17/151) and Pseudomonas aeruginosa $(10.6 \% ; 16 / 151)$. Among Gram-positive bacteria, Staphylococcus aureus $(62.5 \% ; 15 / 24)$ was the most predominant organism, followed by Enterococcus spp. $(33.3 \% ; 8 / 24)$ and Staphylococcus saprophyticus $(4.2 \% ; 1 / 24)$ (Table 1$)$.

Klebsiella spp. was mostly isolated from urine samples $(66.7 \% ; 38 / 57)$, followed by sputum $(29.8 \% ; 17 / 57)$ and pus samples $(3.5 \% ; 2 / 57)$. Males $(57.5 \% ; 23 / 57)$ were more prone to Klebsiella spp. infections than females $(42.5 \%$; $17 / 57)$. Patients of the age group above 60 years were more prone to Klebsiella spp. infections (Table 2). 
Table 1. Distribution of growth pattern of bacterial isolates $(n=175)$.

\begin{tabular}{|c|c|c|}
\hline \multirow[t]{2}{*}{ Specimens/Character } & \multicolumn{2}{|c|}{ Culture Positive } \\
\hline & Number & Percentage \\
\hline \multicolumn{3}{|l|}{ Clinical specimens } \\
\hline Urine $(n=2032)$ & 140 & 80 \\
\hline Sputum $(n=150)$ & 28 & 16 \\
\hline Pus $(n=15)$ & 7 & 4 \\
\hline \multicolumn{3}{|l|}{ Gram type } \\
\hline Gram-negative bacteria & 151 & 86.3 \\
\hline Gram-positive bacteria & 24 & 13.7 \\
\hline \multicolumn{3}{|c|}{ Different type of Gram-positive bacteria $(n=24)$} \\
\hline S. aureus & 15 & 62.5 \\
\hline Enterococcus spp. & 8 & 33.3 \\
\hline S. saprophyticus & 1 & 4.2 \\
\hline \multicolumn{3}{|c|}{ Different type of Gram-negative bacteria $(n=151)$} \\
\hline E. coli & 62 & 41.1 \\
\hline K. pneumoniae & 40 & 26.5 \\
\hline K. oxytoca & 17 & 11.3 \\
\hline P. aeruginosa & 16 & 10.5 \\
\hline Enterobacter aerogenes & 5 & 3.3 \\
\hline Citrobacter fruendii & 4 & 2.6 \\
\hline Morganella morganii & 2 & 1.3 \\
\hline Providencia spp. & 2 & 1.3 \\
\hline Proteus spp. & 1 & 0.7 \\
\hline Haemophilus spp. & 1 & 0.7 \\
\hline Acinetobacter baumannii & 1 & 0.7 \\
\hline \multicolumn{3}{|l|}{ Gender } \\
\hline Male & 92 & 52.5 \\
\hline Female & 83 & 47.5 \\
\hline \multicolumn{3}{|l|}{ Age groups (Years) } \\
\hline $0-15$ & 10 & 5.7 \\
\hline $16-45$ & 80 & 45.7 \\
\hline $46-60$ & 45 & 25.7 \\
\hline$>60$ & 40 & 22.9 \\
\hline
\end{tabular}

Table 2. Distribution of Klebsiella spp. among patients visiting NPHL $(n=57)$.

\begin{tabular}{|c|c|c|c|}
\hline Character & K. pneumoniae $(n=40)$ & K. oxytoca $(n=17)$ & Total \\
\hline & $\mathbf{N}(\%)$ & $\mathbf{N}(\%)$ & N (\%) \\
\hline \multicolumn{4}{|c|}{ Clinical specimens } \\
\hline Urine & $25(62.5)$ & $12(70.6)$ & $37(64.9)$ \\
\hline Sputum & $13(32.5)$ & $5(29.4)$ & 18 (31.6) \\
\hline Pus & $2(5.0)$ & 0 & $2(3.5)$ \\
\hline \multicolumn{4}{|l|}{ Gender } \\
\hline Male & $23(57.5)$ & $9(52.9)$ & $32(56.1)$ \\
\hline Female & $17(42.5)$ & $8(47.1)$ & $25(43.9)$ \\
\hline \multicolumn{4}{|c|}{ Age groups (in years) } \\
\hline $0-15$ & $1(2.5)$ & 0 & $1(1.8)$ \\
\hline $15-45$ & $13(32.5)$ & $7(41.2)$ & $20(35.1)$ \\
\hline $45-60$ & $10(25)$ & $5(29.4)$ & $15(26.3)$ \\
\hline$>60$ & $16(40)$ & $5(29.4)$ & $21(36.8)$ \\
\hline
\end{tabular}

\subsection{Antibiotic Susceptibility Pattern of the Isolates}

Fifteen antibiotics of different classes (on recommendation of CLSI, 2019 guidelines) were tested against Klebsiella spp. Among the antibiotics used, gentamicin was the most 
effective drug $(68.4 \%)$, followed by cotrimoxazole $(47.4 \%)$, ceftriaxone $(45.6 \%)$, tetracycline (45.6\%), ciprofloxacin (42.1\%) and amoxiclav. (33.3\%) (Table 3).

Table 3. Antibiotic susceptibility profile of Klebsiella spp. $(n=57)$.

\begin{tabular}{|c|c|c|c|c|c|}
\hline \multirow{3}{*}{ Mode of Action } & \multirow{3}{*}{ Antimicrobial Category } & \multirow{3}{*}{ Antibiotics } & \multicolumn{3}{|c|}{ K. pneumoniae $(n=57)$} \\
\hline & & & Sensitive & Intermediate & Resistant \\
\hline & & & N (\%) & N (\%) & $\mathbf{N}(\%)$ \\
\hline \multirow{7}{*}{$\begin{array}{c}\text { Cell wall } \\
\text { synthesis inhibitors }\end{array}$} & Aminopenicillin & Amoxiclav $(30 \mu \mathrm{g})$ & $19(33.3)$ & $4(7.1)$ & $34(59.6)$ \\
\hline & \multirow{3}{*}{$\begin{array}{l}\text { Extended spectrum } \\
\text { cephalosporins }\end{array}$} & Ceftriaxone $(30 \mu \mathrm{g})$ & $26(45.6)$ & $2(3.5)$ & $29(50.9)$ \\
\hline & & Cefoxitin $(30 \mu \mathrm{g})$ & $21(36.8)$ & $4(7.0)$ & $32(56.2)$ \\
\hline & & Cefotaxime $(30 \mu \mathrm{g})$ & $26(45.6)$ & $1(1.8)$ & $30(52.6)$ \\
\hline & \multirow{2}{*}{ Carbapenems } & Imipenem $(10 \mu \mathrm{g})$ & $20(35.0)$ & $5(8.8)$ & $32(56.2)$ \\
\hline & & Meropenem $(10 \mu \mathrm{g})$ & $20(35.0)$ & $5(8.8)$ & $32(56.2)$ \\
\hline & $\begin{array}{l}\text { Penicillins and } \\
\text { beta-lactamase inhibitors }\end{array}$ & $\begin{array}{l}\text { Piperacillin-tazobactam } \\
\qquad(100 / 10 \mu \mathrm{g})\end{array}$ & $20(35.0)$ & $6(10.5)$ & $31(54.5)$ \\
\hline \multirow{3}{*}{$\begin{array}{l}\text { Protein synthesis } \\
\text { inhibitors }\end{array}$} & \multirow{2}{*}{ Aminoglycosides } & Amikacin $(30 \mu g)$ & $25(43.9)$ & $3(5.3)$ & $29(50.8)$ \\
\hline & & Gentamicin $(10 \mu \mathrm{g})$ & $39(68.4)$ & $1(1.8)$ & $17(29.8)$ \\
\hline & Tetracyclines & Tetracycline $(30 \mu \mathrm{g})$ & $26(45.6)$ & $5(8.8)$ & $26(45.6)$ \\
\hline \multirow{4}{*}{$\begin{array}{c}\text { Nucleic acid } \\
\text { synthesis inhibitors }\end{array}$} & \multirow{3}{*}{ Fluoroquinolones } & Ciprofloxacin $(5 \mu \mathrm{g})$ & $24(42.1)$ & $3(5.3)$ & $30(52.6)$ \\
\hline & & Norfloxacin $(10 \mu \mathrm{g})$ & $20(35.1)$ & $2(3.5)$ & $35(61.4)$ \\
\hline & & Levofloxacin $(5 \mu \mathrm{g})$ & $21(36.8)$ & $4(7.0)$ & $32(56.2)$ \\
\hline & Nitrofurans & Nitrofurantoin $(300 \mu \mathrm{g})$ & $26(45.6)$ & $6(10.5)$ & $25(43.8)$ \\
\hline Folate pathway inhibitors & $\begin{array}{l}\text { Trimethoprim and } \\
\text { Sulfamethoxazole }\end{array}$ & Cotrimoxazole $(25 \mu \mathrm{g})$ & $27(47.4)$ & $1(1.8)$ & $29(50.9)$ \\
\hline
\end{tabular}

Among the total 57 Klebsiella isolates, 32 (56\%) were MDR, including $26(81.3 \%)$ K. pneumoniae and $6(18.8 \%)$ K. oxytoca isolates (Figure 2).

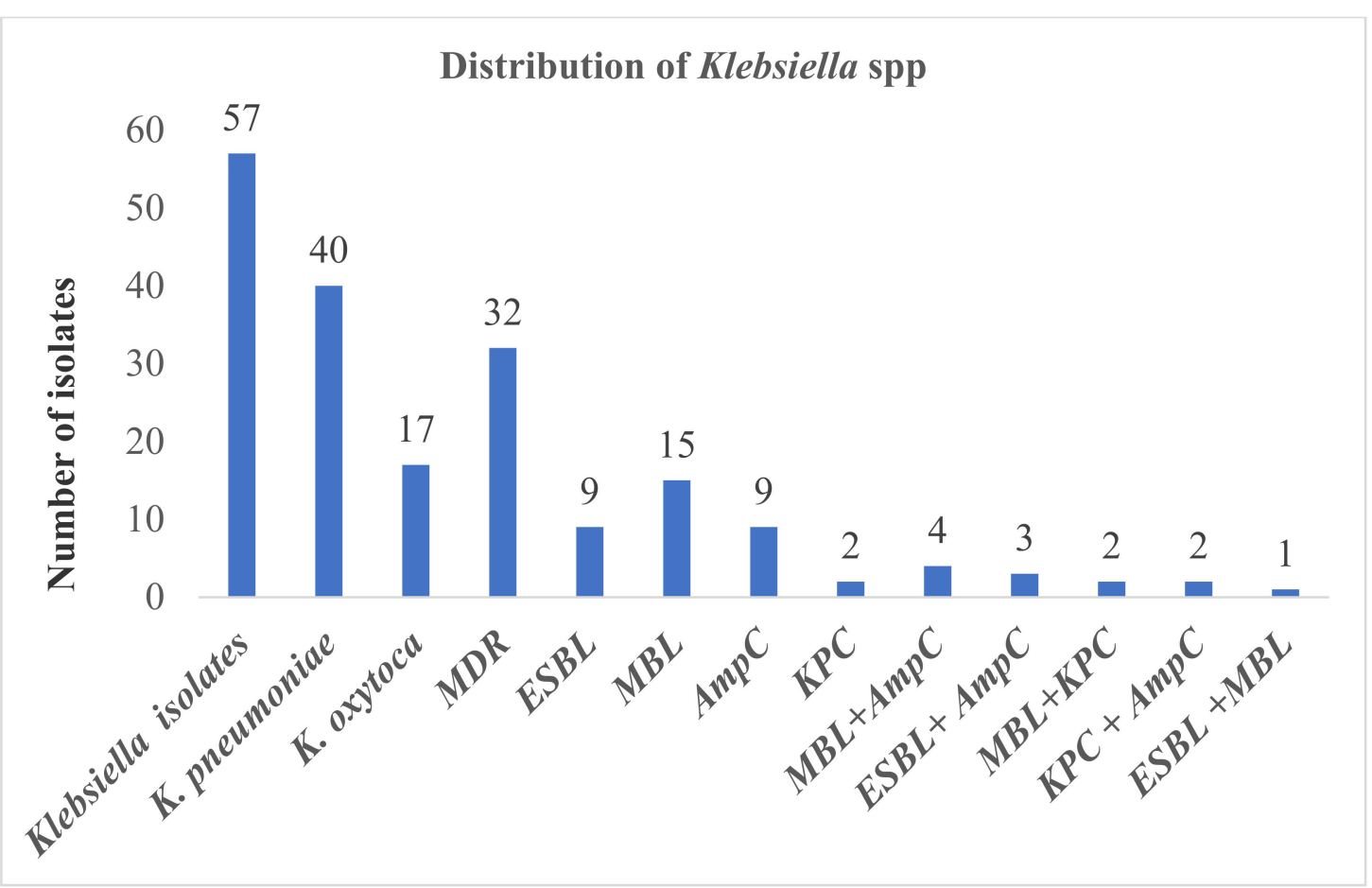

Figure 2. Distribution of ESBL, MBL, AmpC and KPC producing Klebsiella spp. 


\subsection{ESBL, AmpC, MBL, KPC Production among Klebsiella spp.}

Among the total 57 Klebsiella spp. only $9(16 \% ; 9 / 57)$ isolates were confirmed as ESBL producers. The highest percentage of ESBL production was found among K. pneumoniae (7/40; $17.5 \%)$, followed by K. oxytoca $(2 / 17 ; 11.8 \%)$. In the AmpC detection test, $9(16 \%)$ isolates were confirmed as AmpC producers. The highest percentage of AmpC production was found among K. pneumoniae $(8 / 40 ; 20 \%)$, followed by K. oxytoca $(1 / 17 ; 5.9 \%)$. In the MBL test, 15 (26\%) were confirmed as MBL producers. The highest percentage of MBL production was found among K. pneumoniae $(13 / 40 ; 32.5 \%)$, followed by K. oxytoca $(2 / 17$; $11.8 \%)$. In the KPC detection test, only two isolates $(2 / 40 ; 5 \%)$ were confirmed as KPC producing K. pneumoniae (Figure 3).

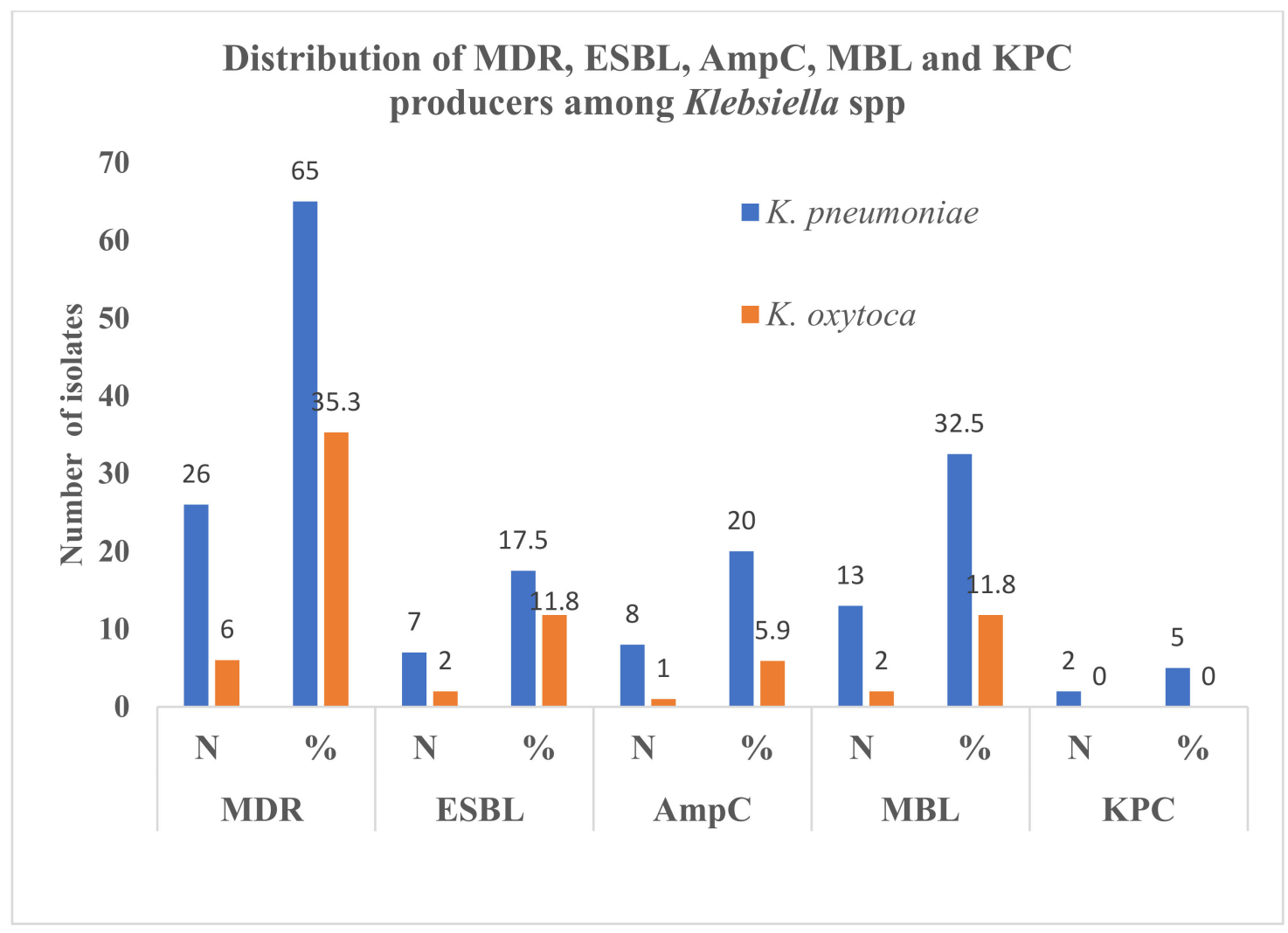

Figure 3. Distribution of MDR, ESBL, AmpC, MBL and KPC producers among Klebsiella isolates $(n=57)$.

\subsection{Distribution of ESBL, AmpC, MBL and KPC Producers in Differential Specimens and Age Groups}

ESBL, AmpC, MBL and KPC were detected in larger proportions in urine samples and among the age group of $16-60$ years. Urine samples constituted $78 \%$ of ESBL, $67 \%$ of AmpC, $60 \%$ of MBL and 50\% of KPC producers. Sputum and pus samples contributed in decreasing order. The age group of 16-60 years alone constituted the $66.7 \%(6 / 9)$ of ESBL, $88.9 \%(8 / 9)$ of AmpC, all (2/2) KPC and 60\% (9/15) of MBL producing isolates. Similarly, $62 \%(20 / 32)$ of MBL and 50\% (1/2) of KPC were detected in urine samples (Table 4).

\subsection{Detection of Biofilm}

Out of 57 Klebsiella isolates, 54 (94.8\%) isolates were confirmed as biofilm producers, of which 4 isolates $(7 \%)$ were strong producers, $34(59.7 \%)$ were moderate and $16(28.1 \%)$ were weak biofilm producers (Table 5). 
Table 4. Demographic and clinical character of MDR, ESBL, AmpC, MBL and KPC producing Klebsiella spp. according to clinical specimens, gender and age.

\begin{tabular}{|c|c|c|c|c|c|}
\hline Character & MDR & ESBL & AmpC & MBL & KPC \\
\hline & N (\%) & N (\%) & N (\%) & N (\%) & $\mathbf{N}(\%)$ \\
\hline \multicolumn{6}{|c|}{ Clinical specimens } \\
\hline Urine & $20(62.5)$ & $7(77.8)$ & $5(55.6)$ & $9(60)$ & $1(50)$ \\
\hline Sputum & $10(31.3)$ & $0(0)$ & $3(33.3)$ & $6(40)$ & $1(50)$ \\
\hline Pus & $2(6.3)$ & $2(22.2)$ & $1(11.1)$ & $0(0)$ & $0(0)$ \\
\hline$p$ value & 0.44 & 0.07 & 0.74 & 0.28 & 0.8 \\
\hline \multicolumn{6}{|l|}{ Gender } \\
\hline Male & $21(65.6)$ & $8(88.9)$ & $4(44.4)$ & $9(60)$ & 0 \\
\hline Female & $11(34.4)$ & $1(11.1)$ & $5(55.6$ & $6(40)$ & $2(100)$ \\
\hline$p$ value & 0.11 & 0.7 & 0.11 & 0.52 & 0.04 \\
\hline \multicolumn{6}{|c|}{ Age groups (in years) } \\
\hline $0-15$ & $1(3.1)$ & $0(0)$ & $0(0)$ & $1(6.7)$ & $0(0)$ \\
\hline $16-45$ & $12(37.5)$ & $4(44.4)$ & $5(55.5)$ & $6(40)$ & $1(50)$ \\
\hline $46-60$ & $8(25)$ & $2(22.2)$ & $3(33.4)$ & $3(20)$ & $1(50)$ \\
\hline$>60$ & $11(34.4)$ & $3(33.3)$ & $1(11.1)$ & $5(33.3)$ & $0(0)$ \\
\hline$p$ value & 0.63 & 0.83 & 0.15 & 0.55 & 0.52 \\
\hline
\end{tabular}

Table 5. Biofilm production among Klebsiella pneumoniae and K. oxytoca isolates in relation to species, clinical specimens, gender and age.

\begin{tabular}{|c|c|c|c|c|c|}
\hline \multirow{3}{*}{ Character } & \multicolumn{3}{|c|}{ Biofilm Producers } & \multicolumn{2}{|c|}{ Biofilm Non-Producers } \\
\hline & Strong & Moderate & Weak & Total Producer & Non-Producer \\
\hline & $\mathbf{N}(\%)$ & $\mathbf{N}(\%)$ & $\mathbf{N}(\%)$ & $\mathbf{N}(\%)$ & $\mathbf{N}(\%)$ \\
\hline Klebsiella spp. (K. pneumoniae and K. oxytoca) & $4(7 \%)$ & $\begin{array}{c}34 \\
(59.7 \%)\end{array}$ & $\begin{array}{c}16 \\
(28.1 \%)\end{array}$ & $54(94.8 \%)$ & $3(5.2 \%)$ \\
\hline K. pneumoniae & $2(50)$ & $24(70.6)$ & $13(81.3)$ & $39(72.2)$ & $1(33.3)$ \\
\hline K. oxytoca & $2(50)$ & $10(29.4)$ & $3(18.8)$ & $17(27.8)$ & $2(66.7)$ \\
\hline \multicolumn{6}{|c|}{ Clinical specimens } \\
\hline Urine & $4(100)$ & $19(55.9)$ & $12(75)$ & $35(64.8)$ & $2(66.7)$ \\
\hline Sputum & $0(0)$ & $13(38.2)$ & $4(24)$ & $17(31.5)$ & $1(33.3)$ \\
\hline Pus & $0(0)$ & $2(5.9)$ & $0(0)$ & $2(3.7)$ & $0(0)$ \\
\hline \multicolumn{6}{|l|}{ Gender } \\
\hline Male & $1(25)$ & $20(58.8)$ & $9(56.3)$ & $30(55.6)$ & $2(66.7)$ \\
\hline Female & $3(75)$ & $14(41.2)$ & $7(43.8)$ & $24(44.4)$ & $1(33.3)$ \\
\hline \multicolumn{6}{|l|}{ Age group (in years) } \\
\hline $0-15$ & $0(0)$ & $0(0)$ & $1(6.3)$ & $1(1.9)$ & $0(0)$ \\
\hline $16-45$ & $2(50)$ & $12(35.3)$ & $5(31.3)$ & $19(35.2)$ & $1(33.3)$ \\
\hline $46-60$ & $1(25)$ & $10(29.4)$ & $4(25)$ & $15(27.7)$ & $0(0)$ \\
\hline$>60$ & $1(25)$ & $12(35.3)$ & $6(37.5)$ & $19(35.2)$ & $2(66.7)$ \\
\hline \multicolumn{6}{|c|}{ Relation of biofilm production according to MDR, ESBL, MBL, AmpC and KPC production } \\
\hline MDR producers & $1(3.1)$ & $21(65.6)$ & $8(25)$ & $30(93.7)$ & $2(6.3)$ \\
\hline ESBL producers & $1(11.1)$ & $5(55.6)$ & $3(33.3)$ & $9(100)$ & $0(0)$ \\
\hline MBL producers & $1(6.7)$ & $8(53.3)$ & $5(33.3)$ & $14(93.3)$ & $1(6.7)$ \\
\hline AmpC producers & $0(0)$ & $7(77.8)$ & $2(22.2)$ & $9(100)$ & $0(0)$ \\
\hline KPC producers & $0(0)$ & $2(100)$ & $0(0)$ & $2(100)$ & $0(0)$ \\
\hline
\end{tabular}

3.6. Biofilm Production among ESBL, AmpC, MBL and KPC Producing Klebsiella spp.

Among total (9) ESBL producers, $1(11 \%)$ was strong, 5 (56\%) were moderate and 3 (33\%) were weak biofilm producers. Similarly, of the total (9) AmpC producing Klebsiella spp., $7(78 \%)$ were moderate and the remaining $2(22 \%)$ were weak producers. Among total (15) MBL producers, $1(6.7 \%)$ was a strong, $8(53.3 \%)$ were moderate and $5(33.3 \%)$ were weak producers. In AmpC producing Klebsiella spp., all (2/2;100\%) were moderate biofilm producers (Table 5). 
3.7. Co-Production of ESBL and AmpC, ESBL and Carbapenemase (MBL and KPC), MBL and $K P C, M B L$ and $A m p C$ and $K P C$ and $A m p C$

Among total MDR Klebsiella spp., 3 (33.3\%) isolates were found to be both ESBL and AmpC producers. Among the total MDR Klebsiella spp., only one (6.7\%) isolate produced both ESBL and MBL. In the study, none of the isolates produced both ESBL and KPC.

All of the imipenem and meropenem-resistant isolates $(2 / 2)$ were also positive in the MBL and KPC production tests. Among MDR Klebsiella species, 4 (44.4\%) produced both MBL and AmpC. Among total MDR Klebsiella species, 2 (22.2\%) isolates produced both KPC and AmpC.

\section{Discussion}

This study was carried out to determine the beta-lactamase enzymes (ESBL, MBL, KPC and AmpC) and biofilm production among Klebsiella spp. from the clinical samples (urine, pus and sputum) obtained at NPHL, Kathmandu. Because of their ability to produce beta-lactamase enzymes and biofilms, Klebsiella spp. are resistant to a wide range of antibiotics [41,42]. As most of the beta-lactamase genes are on plasmid mediated mobile genetic elements, the resistant strains are now disseminating rapidly, leading to increases in mortality, morbidity and healthcare costs [26]. Co-expression of several beta-lactamase genes in an organism may complicate the problem of drug-resistance, thereby limiting treatment options [14]. Detection of these factors and their existing association with drug resistance is crucial in diagnostic laboratories.

In this study, one-third of the isolated Gram-negative bacteria was constituted by Klebsiella spp. This finding was consistent with previous studies [25,26,41-45]. Various factors, such as study location, type of sample, seasonal variation and environmental conditions, including temperature, $\mathrm{pH}$ and humidity of the study site, may be responsible for the difference in the rate of prevalence in other studies [26]. Klebsiella spp. are opportunistic pathogens which cause various infections, such as UTI, pneumonia, blood stream infections and wound infections. In this study, most of the organisms $(66.7 \%)$ were isolated from urine samples, followed by sputum $(29.8 \%)$ and pus $(3.5 \%)$. This may be due to the presence of a large number of urine samples compared with other clinical specimens. Several studies in the past have shown the prominence of urine samples, suggesting the crucial role of Enterobacteriaceae in UTIs in Nepal [25,26,46] and in Spain [47].

In the antibiotic susceptibility test, fifteen antibiotics of different classes were tested against Klebsiella spp. Nitrofurantoin is regarded as having better pharmacokinetics for the treatment of UTIs rather than other infections [48]. Among the antibiotics used, gentamicin was found to be most effective $(68.4 \%)$, followed by cotrimoxazole $(47 \%)$, ceftriaxone (45.6\%), ciprofloxacin (40.7\%) and amoxiclav (33.3\%) against isolates of Klebsiella spp. However, in a study conducted in Iran, the highest resistance was associated with gentamicin and cefepime, whereas the lowest rate was associated with imipenem, meropenem and ceftazidime [42]. Over the years, the prevalence of antimicrobial resistance and MDR has increased to a high level at an alarming rate in Nepal [49]. Our study also reported more than half of the total isolated Klebsiella spp. as MDR. This study is in harmony with previous studies from Indonesia [50] and Brazil [51].

Samples were screened for ESBL, MBL, KPC and AmpC $\beta$ lactamase and more than half of the Klebsiella spp. isolates were found positive, but the percentage was lower during confirmatory tests. However, the detected load of ESBL is still enough to challenge a number of treatment regimens. The more clinically important species, K pneumoniae was the dominant $(17.5 \%)$ producer of ESBL over K. oxytoca $(12 \%)$. This finding of higher prevalence of ESBL producers is similar to previous studies reported from Kathmandu [25], Birgunj [52], Model Hospital, Kathmandu [53] and Taiwan [54]. The factors leading to the high prevalence of ESBL producers could be indwelling catheters, invasive procedures and excessive use of cephalosporins and severity of the illness [55]. The AmpC production test was conducted using the inhibitor-based method using phenyl boronic acid (PBA) [38]. A 
significant number of isolates of both species (K. pneumoniae and K. oxytoca) were screened and tested positive, which is consistent with the previous studies from Nepal $[27,56,57]$.

Although carbapenems are the last choice for the treatment of isolates producing ESBL and $\mathrm{AmpC}$, the proportion of carbapenem resistant Klebsiella spp. is on the rise [58]. Our study reported $56 \%$ imipenem and meropenem resistant Klebsiella spp., $26 \%$ of which tested positive for MBL and 3.5\% of which were KPC producers. The findings of our study are in line with the studies reported from India [59-61], but contrast with other studies reported from Nepal [26,62]. This might be due to variation in study sites, nature of illnesses and the clinical specimens.

The occurrence of multiple $\beta$-lactamases among bacteria was also observed. In this study, $3(33.3 \%)$ isolates were found to be ESBL and AmpC producers having similarity with a study in Taiwan [54]. Similarly, in our study, $6.7 \%$ isolates were co-producers of ESBL and MBL; 22\% were KPC and AmpC producers and, of 2 KPC isolates, both isolates were co-producers with MBL and AmpC $\beta$ lactamase. The relationship of co-occurrence among the pairs ESBL and MBL and MBL and KPC was statistically significant. The maximum percentages of ESBL, AmpC, MBL and KPC producers were found in urine samples. The significant association among these parameters was also explained in some other studies [14]. This may be due to involvement of more study subjects with complaints of UTIs, thus inclusion of urine as the largest sample size in our study.

Biofilm production in this study was found in $95 \%$ Klebsiella spp. with more than half of the total biofilm producers being MDR. In contrast to our findings, other studies have reported, comparably, more strong biofilm producers than ours does [63,64]. Biofilm producers were found to be highly resistant to cefotaxime, levofloxacin, piperacillin-tazobactam and imipenem $(80 \%)$. Gentamicin was an effective drug against these recalcitrant strains. However, varying degrees of antibiotic resistance by biofilm producing isolates were observed in some other studies reported from Nepal [49,65].

\section{Strengths and Limitations}

This study should serve as a valuable reference for future studies determining the prevalence of ESBL, MBL, KPC, AmpC $\beta$ lactamase and biofilm producers. This study compiled a set of enzymes, their prevalence and their relationships. The findings and conclusions may be a reference tool for policy makers and clinicians to design and implement treatment regimens.

There are several limitations to this study. As this study was conducted in a single laboratory, studies with large numbers of study samples, at multiple healthcare facilities and communities would be desirable to estimate the actual burden of antimicrobial resistance (AMR) in the country. As our study relied on phenotypic methods for detection of enzymes, further analysis with molecular detection of responsible genes and their characterization would be more sensitive and reliable. Although a large sample was screened $(n=2197)$, the study ended up with only 57 Klebsiella species, which limited the statistical analyses and inferences.

\section{Conclusions}

The detection of a high prevalence of beta-lactamase enzymes and biofilm production among isolated Klebsiella species in our study showed the important roles of these factors in conferring resistance. The co-expression of any of these factors together potentially further reinforces the multi-drug resistance among bacterial isolates against the routinely used antibiotics, such as beta-lactams and carbapenems. Since there is no single diagnostic method (either phenotypic or genotypic when used alone) which has ideal (100 percent) sensitivity and specificity, an algorithm approach, or the integration of molecular/genotypic tests in addition to the routine diagnostic procedures can help in the early detection and management of infections caused by resistant isolates. In addition to antibiotic therapy, anti-biofilm approaches (chelating agents and lantibiotics) could be considered to inform the best treatment options. 
Author Contributions: All authors made substantial contributions to the study. S.K., P.G. and K.R.R. conceived and designed the study; P.G. helped in the acquisition of funding; S.K. collected samples, investigated, and recorded the laboratory findings; J.A., N.A., M.R.B. and U.T.S. supervised the laboratory work; B.D., K.R.R., M.R.B., S.A. and P.G. advised and formulated the methodology for the study; B.D. and K.R.R. drafted the original version of this manuscript; B.D. and K.R.R. are responsible for reviewing several versions of the manuscript. All authors have read and agreed to the published version of the manuscript.

Funding: This research was supported by the University Grants Commission, Nepal (UGC-Nepal), Bhaktapur, through a collaborative grant under Professor Dr. Prakash Ghimire (UGC Grant No.CRG74/75-S\&T-02). Strict adherence to the ethical guidelines was adopted and we declare that this research is free from interest of funding providers.

Institutional Review Board Statement: This study was approved by the Institutional Review Committee (IRC) of the Institute of Science and Technology (IOST) (Reference Number IRC/IOST-9/2019), Tribhuvan University, Kirtipur, Kathmandu. Written informed consent was obtained from all human participants involved in this study. Parents/legal guardians provided consent for pediatric/minor subjects included in the study. This study was conducted in accordance with the Declaration of Helsinki.

Informed Consent Statement: Written informed consent was obtained from all subjects involved in the study.

Data Availability Statement: All the data pertaining to this study are within the manuscript.

Acknowledgments: We would like to express our sincere gratitude and admiration to all the staff and faculty of the Central Department of Microbiology, Tribhuvan University, Kathmandu, and National Public Health Laboratory, Kathmandu, for their support and guidance to complete this study. We are grateful to the patients for their involvement in the study. We would like to express our sincere gratitude to the University Grant Commission (UGC-Nepal) for its support through the Collaborative Research Grant 2074-75-CRG-74/75-S\&T-02, enabling us to investigate antimicrobial resistance in Nepal and contribute to the global database of concern. We would like to express our gratitude to Gordon Tambellini, USA, for proof reading and edits.

Conflicts of Interest: All the authors declared that they have no competing interests.

Consent for Publication : Written informed consent was obtained from all study subjects to publish this paper.

\begin{abstract}
Abbreviations
AMR, antimicrobial resistance; AST, antibiotic susceptibility test; ATCC, American Type Culture Collection; BA, blood agar; CDC, Center for Disease Control; CLED, Cysteine lactose electrolyte deficient; CLSI, Clinical Laboratory Standard Institute; CTX-M, Cefotaxime, Munich; ECDC, European Centre for Disease Prevention and Control; EDTA, Ethylene Diamine Tetra acetic acid; ESBL, Extended Spectrum Beta Lactamase; GES-1, Guaiana Expended Spectrum; GIM, German imipenemase; OXA, Oxacillin-hydrolyzing; KPC, Klebsiella pneumoniae Carbapenemase; MBL, Metallo-betalactamase; MDR, multi-drug resistance/resistant; MHA, Mueller-Hinton Agar; MIC, minimum inhibitory concentrations; NA, nutrient agar; NDM, New Delhi Metallo-beta-lactamase; NPHL, National Public Health laboratory; PBA, Phenyl Boronic Acid; PER, Pseudomonas extended resistance; SHV, Sulfhydryl Variable; SIM, Seoul Imipenemase; SPM-1, Sao Paulo Metallo-beta lactamase; TEM, Temocillin-hydrolyzing; VEB, Vietnamase Extended Spectrum Beta lactamase; VIM, Verona integron encoded metallo-beta lactamase.
\end{abstract}

\title{
References
}

1. Afzal, A.M.S. Antibiotic resistant pattern of E. coli and Klebsiella species in Pakistan: Brief overview. J. Microb. Biochem. Technol. 2017, 9, 277-279.

2. Martínez, J.; Martínez, L.; Rosenblueth, M.; Silva, J.; Martinez-Romero, E. How are gene sequence analyses modifying bacterial taxonomy? The case of Klebsiella. Int. Microbiol. 2004, 7, 261-268. [PubMed]

3. Podschun, R.; Ullmann, U. Klebsiella spp. as nosocomial pathogens: Epidemiology, taxonomy, typing methods, and pathogenicity factors. Clin. Microbiol. Rev. 1998, 11, 589-603. [CrossRef] 
4. Namratha, K.G.; Sreeshma, P.; Subbannayya, K.; Dinesh, P.V.; Champa, H. Characterization and antibiogram of Klebsiella spp. isolated from clinical specimen in a rural teaching hospital. Sch. J. App. Med. Sci. 2015, 3, 878-883.

5. Lederman, E.R.; Crum, N.F. Pyogenic liver abscess with a focus on Klebsiella pneumoniae as a primary pathogen: An emerging disease with unique clinical characteristics. Am. J. Gastroenterol. 2005, 100, 322-331. [CrossRef]

6. Bonelli, R.R.; Moreira, B.M.; Picao, R.C. Antimicrobial resistance among Enterobacteriaceae in South America: History, current dissemination status and associated socioeconomic factors. Drug Resist. Updates 2014, 17, 24-36. [CrossRef] [PubMed]

7. World Health Organization (WHO). Antimicrobial Resistance: Global Report on Surveillance. 2014. Geneva. Available online: https:/ / www.who.int/antimicrobial-resistance/publications/surveillancereport/en/ (accessed on 15 March 2020).

8. Paczosa, M.K.; Mecsas, J. Klebsiella pneumoniae: Going on the Offense with a Strong Defense. Microbiol. Mol. Biol. Rev. 2016, 80, 629-661. [CrossRef]

9. Azzopardi, E.A.; Ferguson, E.L.; Thomas, D.W. The enhanced permeability retention effect: A new paradigm for drug targeting in infection. J. Antimicrob. Chemother. 2013, 68, 257-274. [CrossRef]

10. Macia, M.D.; Rojo-Molinero, E.; Oliver, A. Antimicrobial susceptibility testing in biofilm-growing bacteria. Clin. Microbiol. Infect. 2014, 20, 981-990. [CrossRef]

11. Sadekuzzaman, M.; Yang, S.; Mizan, F.R.; Ha, S.; Sadekuzzaman, M.; Yang, S.; Mizan, F.R.; Ha, S. Current and recent advanced strategies for combating biofilms. Compr. Rev. Food Sci. Food Saf. 2015, 14, 491-509. [CrossRef]

12. Boddicker, J.D.; Anderson, R.A.; Jagnow, J.; Clegg, S. Signature-tagged mutagenesis of Klebsiella pneumoniae to identify genes that influence biofilm formation on extracellular matrix material. Infect. Immun. 2006, 74, 4590-4597. [CrossRef] [PubMed]

13. Balestrino, D.; Ghigo, J.M.; Charbonnel, N.; Haagensen, J.A.; Forestier, C. The characterization of functions involved in the establishment and maturation of Klebsiella pneumoniae in vitro biofilm reveals dual roles for surface exopolysaccharides. Environ. Microbiol. 2008, 10, 685-701. [CrossRef]

14. Raut, S.; Gokhale, S.; Adhikari, B. Prevalence of extended spectrum beta-lactamases among E. coli and Klebsiella spp. isolates in Manipal Teaching Hospital, Pokhara, Nepal. J. Microbiol. Infect. Dis. 2015, 5, 69-75. [CrossRef]

15. Yusuf, I.; Haruna, M.; Yahaya, H. Prevalence and antibiotic susceptibility of AmpC and ESBL producing clinical isolates at a tertiary health care center in Kano, North west Nigeria. Afr. J. Exp. Microbiol. 2013, 14, 109-119. [CrossRef]

16. Paterson, D.L. Resistance in gram-negative bacteria: Enterobacteriaceae. Am. J. Med. 2006, 119, S20-S28. [CrossRef] [PubMed]

17. Kuenzli, E.; Jaeger, V.K.; Frei, R.; Neumayr, A.; DeCrom, S.; Haller, S.; Blum, J.; Widmer, A.F.; Furrer, H.; Battegay, M.; et al. High colonization rates of extended-spectrum beta-lactamase (ESBL)-producing Escherichia coli in Swiss travellers to South Asia- a prospective observational multicentre cohort study looking at epidemiology, microbiology and risk factors. BMC Infect. Dis. 2014, 14, 528. [CrossRef]

18. Harris, P.N.; Peleg, A.Y.; Iredell, J.; Ingram, P.R.; Miyakis, S.; Stewardson, A.J.; Rogers, B.A.; McBryde, E.S.; Roberts, J.A.; Lipman, J.; et al. Meropenem versus piperacillin-tazobactam for definitive treatment of bloodstream infections due to ceftriaxone non-susceptible Escherichia coli and Klebsiella spp (the MERINO trial): Study protocol for a randomised controlled trial. Trials 2015, 16, 24. [CrossRef] [PubMed]

19. Azimi, L.; Rastegar-Lari, A.; Talebi, M.; Ebrahimzadeh-Namvar, A.; Soleymanzadeh-Moghadam, S. Evaluation of phenotypic methods for detection of Klebsiella pneumoniae carbapenemase-producing K. pneumoniae in Tehran. J. Med. Bacteriol. 2013, 2, 26-31.

20. Chaudhary, A.K.; Bhandari, D.; Amatya, J.; Chaudhary, P.; Acharya, B. Metallo-beta-lactamase producing Gram negative bacteria among patients visiting Shahid Gangalal National Heart Central. Austin J. Microbiol. 2016, 2, 1010.

21. Mishra, S.K.; Acharya, J.; Kattel, H.P.; Koirala, J.; Rijal, B.P.; Pokhrel, B.M.; Mishra, S.K.; Acharya, J.; Kattel, H.P.; Koirala, J.; et al. Metallo-beta-lactamase producing gram-negative bacterial isolates. J. Nepal Health Res. Counc. 2012, 10, 208-213. [PubMed]

22. Marchaim, D.; Navon-Venezia, S.; Schwaber, M.J.; Carmeli, Y. Isolation of imipenem-resistant Enterobacter species: Emergence of KPC-2 carbapenemase, molecular characterization, epidemiology, and outcomes. Antimicrob. Agents Chemother. 2008, 52, 1413-1418. [CrossRef]

23. Fisher, M.A.; Stamper, P.D.; Hujer, K.M.; Love, Z.; Croft, A.; Cohen, S.; Bonomo, R.A.; Carroll, K.C.; Petti, C.A. Performance of the Phoenix bacterial identification system compared with disc diffusion methods for identifying extended-spectrum beta-lactamase, AmpC and KPC producers. J. Med. Microbiol. 2009, 58, 774-778. [CrossRef] [PubMed]

24. Sanchez, G.V.; Master, R.N.; Clark, R.B.; Fyyaz, M.; Duvvuri, P.; Ekta, G.; Bordon, J. Klebsiella pneumoniae antimicrobial drug resistance, United States, 1998-2010. Emerg. Infect. Dis. 2013, 19, 133-136. [CrossRef] [PubMed]

25. Kayastha, K.; Dhungel, B.; Karki, S.; Adhikari, B.; Banjara, M.R.; Rijal, K.R.; Ghimire, P. Extended-Spectrum beta-LactamaseProducing Escherichia coli and Klebsiella species in pediatric patients visiting International Friendship Children's Hospital, Kathmandu, Nepal. Infect. Dis. (Auckl.) 2020, 13, 1178633720909798. [PubMed]

26. Dhungana, K.; Awal, B.K.; Dhungel, B.; Sharma, S.; Banjara, M.R.; Rijal, K.R. Detection of Klebsiella pneumoniae carbapenemase (KPC) and metallo betalactamae (MBL) producing Gram negative bacteria isolated from different clinical samples in a Transplant Center, Kathmandu, Nepal. ASMI 2019, 2, 60-69.

27. Guragain, N.; Pradhan, A.; Dhungel, B.; Banjara, M.R.; Rijal, K.R.; Ghimire, P. Extended spectrum B-lactamase producing Gram negative bacterial isolates from urine of patients visiting Everest Hospital, Kathmandu, Nepal. TUJM 2019, 6, 26-31. [CrossRef]

28. Raut, S.; Rijal, K.R.; Khatiwada, S.; Karna, S.; Khanal, R.; Adhikari, J.; Adhikari, B. Trend and characteristics of Acinetobacter baumannii infections in patients attending Universal College of Medical Sciences, Bhairahawa, Western Nepal: A longitudinal study of 2018. Infect. Drug Resist. 2020, 13, 1631-1641. [CrossRef] 
29. Gurung, S.; Kafle, S.; Dhungel, B.; Adhikari, N.; Shrestha, U.T.; Adhikari, B.; Banjara, M.R.; Rijal, K.R.; Ghimire, P. Detection of OXA-48 gene in carbapenem-resistant Escherichia coli and Klebsiella pneumoniae from urine samples. Infect. Drug Resist. 2020, 13, $2311-2321$. [CrossRef] [PubMed]

30. Parajuli, N.P.; Acharya, S.P.; Mishra, S.K.; Parajuli, K.; Rijal, B.P.; Pokhrel, B.M. High burden of antimicrobial resistance among Gram negative bacteria causing healthcare associated infections in a critical care unit of Nepal. Antimicrob. Resist. Infect. Control 2017, 6, 67. [CrossRef]

31. Isenberg, H.D. Clinical Microbiology Procedures Handbook, 2nd ed.; ASM Press: Washington, DC, USA, 2004.

32. Cheesbrough, M. District Laboratory Practice in Tropical Countries, 2nd ed.; Cambridge University Press: Cambridge, UK, 2005.

33. Forbes, B.A.; Sahm, D.F.; Weissfelt, S.A. Bailey and Scott's Diagnostic Microbiology; Mosby Publication: St. Louis, MO, USA, 2007.

34. Clinical and Laboratory Standards Institute. Performance Standards for Antimicrobial Susceptibility Testing, 28th ed.; Informational supplement M100-S28; Clinical and Laboratory Standards Institute: Wayne, PA, USA, 2018.

35. Magiorakos, A.P.; Srinivasan, A.; Carey, R.B.; Carmeli, Y.; Falagas, M.E.; Giske, C.G.; Harbarth, S.; Hindler, J.F.; Kahlmeter, G.; Olsson-Liljequist, B.; et al. Multidrug-resistant, extensively drug-resistant and pandrug-resistant bacteria: An international expert proposal for interim standard definitions for acquired resistance. Clin. Microbiol. Infect. 2012, 18, 268-281. [CrossRef]

36. Panchal, C.A.; Oza, S.S.; Mehta, S.J. Comparison of four phenotypic methods for detection of metallo-beta-lactamase-producing Gram-negative bacteria in rural teaching hospital. J. Lab. Physicians 2017, 9, 81-83.

37. Tsakris, A.; Poulou, A.; Pournaras, S.; Voulgari, E.; Vrioni, G.; Themeli-Digalaki, K.; Petropoulou, D.; Sofianou, D. A simple phenotypic method for the differentiation of metallo-beta-lactamases and class A KPC carbapenemases in Enterobacteriaceae clinical isolates. J. Antimicrob. Chemother. 2010, 65, 1664-1671. [CrossRef]

38. Coudron, P.E. Inhibitor-based methods for detection of plasmid-mediated AmpC beta-lactamases in Klebsiella spp., Escherichia coli, and Proteus mirabilis. J. Clin. Microbiol. 2005, 43, 4163-4167. [CrossRef]

39. Stepanović, S.; Vuković, D.; Dakić, I.; Savić, B.; Švabić-Vlahović, M. A modified microtiter-plate test for quantification of Staphylococcal biofilm formation. J. Microbiol. Methods 2000, 40, 175-179. [CrossRef]

40. Lamichhane, K.; Adhikari, N.; Bastola, A.; Devkota, L.; Bhandari, P.; Dhungel, B.; Shrestha, U.T.; Adhikari, B.; Banjara, M.R.; Rijal, K.R.; et al. Biofilm-Producing Candida Species Causing Oropharyngeal Candidiasis in HIV Patients Attending Sukraraj Tropical and Infectious Diseases Hospital in Kathmandu, Nepal. HIV AIDS (Auckl.) 2020, 12, 211-220. [CrossRef] [PubMed]

41. Poudyal, S.; Bhatta, D.R.; Shakya, G.; Upadhyaya, B.; Dumre, S.P.; Buda, G.; Kandel, B.P. Extended spectrum a-lactamase producing multidrug resistant clinical bacterial isolates at National Public Health Laboratory, Nepal. Nepal Med. Coll. J. 2011, 13, 34-38. [PubMed]

42. Bina, M.; Pournajaf, A.; Mirkalantari, S.; Talebi, M.; Irajian, G. Detection of the Klebsiella pneumoniae carbapenemase (KPC) in K. pneumoniae isolated from the clinical samples by the phenotypic and genotypic methods. Iran. J. Pathol. 2015, 10, 199-205. [PubMed]

43. Sah, R.S.P.; Dhungel, B.; Yadav, B.K.; Adhikari, N.; Thapa Shrestha, U.; Lekhak, B.; Banjara, M.R.; Adhikari, B.; Ghimire, P.; Rijal, K.R. Detection of TEM and CTX-M Genes in Escherichia coli Isolated from Clinical Specimens at Tertiary Care Heart Hospital, Kathmandu, Nepal. Diseases 2021, 9, 15. [CrossRef]

44. Tamang, K.; Shrestha, P.; Koirala, A.; Khadka, J.; Gautam, N.; Rijal, K.R. Prevalence of bacterial uropathogens among diabetic patients attending Padma Nursing Hospital of Western Nepal. HiJOST 2017, 1, 15-19. [CrossRef]

45. Thakur, P.; Ghimire, P.; Rijal, K.R.; Singh, G.K. Antimicrobial resistance pattern of Escherichia coli isolated from urine samples in patients visiting tertiary health care centre in eastern Nepal. Sunsari Tech. Coll. J. 2012, 1, 22-26. [CrossRef]

46. Adhikari, S.; Khadka, S.; Rana, J.C.; Baniya, S.; Poudel, S.; Chapagain, A.; Regmi, R. Prevalence of $\beta$-Lactamase producing carbapenem-resistant Enterobacteriaceae among the patients attending Bharatpur Hospital. Biosci. Dis. 2019, $10,64-71$.

47. Pérez-Vazquez, M.; Oteo-Iglesias, J.; Sola-Campoy, P.J.; Carrizo-Manzoni, H.; Bautista, V.; Lara, N.; Aracil, B.; Alhambra, A.; Martínez-Martínez, L.; Campos, J.; et al. Characterization of carbapenemase-producing Klebsiella oxytoca in Spain, $2016-2017$. Antimicrob. Agents Chemother. 2019, 63, e02529-18. [CrossRef]

48. Munoz-Davila, M.J. Role of old antibiotics in the era of antibiotic resistance. Highlighted nitrofurantoin for the treatment of lower urinary tract infections. Antibiotics 2014, 3, 39-48. [CrossRef]

49. Rijal, K.R.; Banjara, M.R.; Dhungel, B.; Kafle, S.; Gautam, K.; Ghimire, B.; Ghimire, P.; Dhungel, S.; Adhikari, N.; Shrestha, U.T.; et al. Use of antimicrobials and antimicrobial resistance in Nepal: A nationwide survey. Sci. Rep. 2021, 11, 11554. [CrossRef]

50. Nirwati, H.; Sinanjung, K.; Fahrunissa, F.; Wijaya, F.; Napitupulu, S.; Hati, V.P.; Hakim, M.S.; Meliala, A.; Aman, A.T.; Nuryastuti, T. Biofilm formation and antibiotic resistance of Klebsiella pneumoniae isolated from clinical samples in a tertiary care hospital, Klaten, Indonesia. BMC Proc. 2019, 13, 20. [CrossRef] [PubMed]

51. Ferreira, R.L.; da Silva, B.; Rezende, G.S.; Nakamura-Silva, R.; Pitondo-Silva, A.; Campanini, E.B.; Brito, M.C.; da Silva, E.M.; Freire, C.C.; Cunha, A.F.; et al. High prevalence of multidrug-resistant Klebsiella pneumoniae harboring several virulence and beta-lactamase encoding genes in a Brazilian Intensive Care Unit. Front. Microbiol. 2018, 9, 3198. [CrossRef]

52. Upadhyay, A.K.; Parajuli, P. Extended spectrum $\beta$-lactamases producing Klebsiella species isolated at National Medical College and Teaching Hospital, Nepal. Asian J. Pharma Clin. Res. 2013, 1, 161-164.

53. Shrestha, U.T.; Shrestha, S.; Adhikari, N.; Rijal, K.R.; Shrestha, B.; Adhikari, B.; Banjara, M.R.; Ghimire, P. Plasmid profiling and occurrence of $\beta$-lactamase enzymesin multidrug-resistant uropathogenic Escherichia coli in Kathmandu, Nepal. Infect. Drug Resist. 2020, 13, 1905-1917. 
54. Shu, J.C.; Chia, J.H.; Kuo, A.J.; Su, L.H.; Wu, T.L. A 7-year surveillance for ESBL-producing Escherichia coli and Klebsiella pneumoniae at a university hospital in Taiwan: The increase of CTX-M-15 in the ICU. Epidemiol. Infect. 2010, 138, 253-263. [CrossRef]

55. Jain, A.; Roy, I.; Gupta, M.K.; Kumar, M.; Agarwal, S.K. Prevalence of extended-spectrum beta-lactamase-producing Gramnegative bacteria in septicaemic neonates in a tertiary care hospital. J. Med. Microbiol. 2003, 52, 421-425. [CrossRef] [PubMed]

56. Baral, P.; Neupanea, S.; Shresthac, B.; Ghimirea, K.R.; Marasinia, B.P.; Lekhaka, B. Clinical and microbiological observational study on AmpC beta-lactamase-producing Enterobacteriaceae in a hospital of Nepal. Braz. J. Infect. Dis. 2013, 17, 256-259. [CrossRef]

57. Bhandari, P.; Thapa, G.; Pokhrel, B.M.; Bhatta, D.R.; Devkota, U. Nosocomial isolates and their drug resistant pattern in ICU patients at National Institute of Neurological and Allied Sciences, Nepal. Int. J. Microbiol. 2015, 2015, 572163. [CrossRef] [PubMed]

58. Meletis, G. Carbapenem resistance: Overview of the problem and future perspectives. Adv. Infect. Dis 2016, 3, 15-21. [CrossRef]

59. Gupta, V.; Bansal, N.; Singla, N.; Chander, J. Occurrence and phenotypic detection of class A carbapenemases among Escherichia coli and Klebsiella pneumoniae blood isolates at a tertiary care center. J. Microbiol. Immunol. Infect. 2013, 46, 104-108. [CrossRef] [PubMed]

60. Chauhan, K.; Pandey, A.; Asthana, A.K.; Madan, M. Evaluation of phenotypic tests for detection of Klebsiella pneumoniae carbapenemase and metallo-beta-lactamase in clinical isolates of Escherichia coli and Klebsiella species. Indian J. Pathol. Microbiol. 2015, 58, 31-35.

61. Mohamudha Parveen, R.; Harish, B.N.; Parija, S.C. AmpC Beta lactamases among gram negative clinical isolates from a tertiary hospital, South India. Braz. J. Microbiol. 2010, 41, 596-602. [CrossRef] [PubMed]

62. Khanal, S.; Joshi, D.R.; Bhatta, D.R.; Devkota, U.; Pokhrel, B.M. Beta-lactamase-producing multidrug-resistant bacterial pathogens from tracheal aspirates of Intensive Care Unit patients at National Institute of Neurological and Allied Sciences, Nepal. ISRN Microbiol. 2013, 2013, 847569. [CrossRef]

63. Rahdar, H.A.; Malekabad, E.S.; Dadashi, A.-R.; Takei, E.; Keikha, M.; Kazemian, H.; Karami-Zarandi, M. Correlation between biofilm formation and carbapenem resistance among clinical isolates of Klebsiella pneumoniae. Ethiop. J. Health Sci. 2019, 29, 745-750. [CrossRef]

64. Sanchez, C.J., Jr.; Mende, K.; Beckius, M.L.; Akers, K.S.; Romano, D.R.; Wenke, J.C.; Murray, C.K. Biofilm formation by clinical isolates and the implications in chronic infections. BMC Infect. Dis. 2013, 13, 47. [CrossRef]

65. Thapa, S.; Neopane, P.; Shrestha, R. Biofilm formation and antimicrobial resistance in Klebsiella pneumoniae isolated from patient visiting a tertiary care center of Nepal. Asian Pac. J. Trop. Dis. 2017, 7, 347-351. 